Поповичева М., Баркаси Д.

\title{
Нагрузка медсестёр в лечебном учреждении при уходе за пациентами
}

Высшая школа здравоохранения и социальной работы св. Алжбеты, н.о. филиал бл. Метода Доминика Тричку, г. Братислава, Словакия

maria.popovic911@gmail.com, daniela.barkasi@gmail.com

\author{
Поповічева М., Баркасі Д. \\ Навантаження медсестер в лікувальних закладах \\ при догляді за пацієнтами \\ Вища школа охорони здоров'я та соціальної роботи \\ св. Алжбети, н.о. філія бл. Методу Домініка Трічку, \\ м. Братислава, Словаччина
}

Popovichova M., Barkasi D.

The ballast of nurses in the provision

of nursing care in a hospital

Medical University of Health and Social Work Algeria, n.o., branch of bl. Methods of Dominic Trchku,

Bratislava, Slovakia

\section{Введение}

Профессия медсестры - одна из самых востребованных и многозатратых. Медсестры являются неотъемлемым и очень важным членом медицинской команды. Образно говоря, они его «костяк». Работа медсестры связана с высокими требованиями к выполняемой работе, высокой ответственностью, постоянным стрессом, недооцененностю или сложными межличностными отношениями. Это связано с высоким уровнем эмоционального напряжения, то есть с потенциальным ущербом для здоровья и низким уровнем удовлетворенности работой. Эта профессия всегда требовала не только больших умственных, но так же больших физических затрат. Несмотря на то, что существуют нормы для медицинского персонала, мы знаем, что они часто не соблюдаются. В больницах не хватает вспомогательного персонала, что влияет на работу медсестры, потому что они нагружаются и другими обязанностями. Эта работа отнимает у них время, которое они могли бы посвятить профессиональной деятельности или общению с пациентом. От них ожидают не только отличных результатов, но и эмпатического подхода, личной заинтересованности при оказании сестринской помощи или обучения в течение всей жизни и приобретения новых навыков. Источником нагрузки для медсестры также может быть плохое управление работой, плохая организационная структура или неудовлетворительная социальная атмосфера на рабочем месте. Это профессия, в которой медсестра находится в постоянном контакте со многими стрессовыми факторами. Они находятся в ежедневном контакте с болью, страданием, смертью. Причины психологического стресса могут быть основаны на собственно работе медсестры или ее личной жизни. Это переутомление может привести к выгоранию.

\section{Физическая нагрузка медсестер}

Мы характеризуем физическую активность как рабочую нагрузку на костно-мышечную, сердечнососудистую и дыхательную системы с отражением в обмене веществ и терморегуляции. Современная тенденция развития условий труда приводит к сокращению доли физически тяжелой работы и, наоборот, к увеличению психического напряжения. Тем не менее, существуют профессии, в которых физическая нагрузка все еще остается значительной, и в эти профессии также входит профессия медсестры. Поскольку медсестра ходит или стоит большую часть рабочего времени, костномышечная система наиболее подвержена физическим нагрузкам. У них часто наблюдается варикозное расширение вен, боли в ногах и суставах. При работе с неподвижным пациентом позвоночник и верхние конечности наиболее подвержены нагрузке [1]. Что касается подъема пациента, должен быть задан вопрос: является ли пациент бременем. В других профессиях, таких как работники почты, в магазине и т.д. согласно законам, женщины могут поднимать груз до 15 кг. Но в больнице часто 50-килограммовые медсестры только своими руками поднимают 100-килограммовых пациентов, которые обездвижены.

\section{Психосоциальная нагрузка медсестер}

Человек - живое существо, динамичная личность, но с другой стороны, очень чувствительная и уязвимая личность. Эти качества применимы к медсестре, которая на основе «мягких» навыков проявляет эмпатию и сочувствие к пациенту, это значит что она хочет создать маленький кусочек мира, в котором она находит лучшее и светлое. Поэтому профессия медсестры утомительна, и вызывает стресс [2]. Психосоциальная нагрузка является профессиональной составляющей в работе медсестры. Это отношения между медсестрой и пациентом, медсестрой и членами семьи, а также медсестрой и коллегами. 
В рабочих отношениях часто возникают конфликты между врачом и медсестрой, когда врач не считает медсестру равноправным партнером и часто заставляет почувствовать субординацию. Он также делегирует свои медицинские полномочия таким образом, чтобы медсестра не могла эффективно защищать себя [3]. Эти факты связаны не с личностью медсестры или врача, а с неопределёнными границами их компетенции. Мы часто обнаруживаем, что даже медсестёр с университетским образованием врачи не считают равными членами команды. Плохая организация работы, отсутствие обратной связи со стороны руководителей, низкий уровень оценки со стороны начальства, ссоры, оскорбления в команде, отсутствие взаимного доверия, проявление зависти или неуважение к людям также оказывают негативное и обременительное влияние на медсестру. Ситуации, связанные с контактом с тяжело больными и умирающими людьми и их семьями, также являются источником сильного психосоциального напряжения. Они часто переносят свое беспокойство, состояния тревоги и гнев на медсестру. Мы также можем рассматривать паллиативную помощь как одну из психологически сложных областей медицины, когда состояние пациента очень серьезное и прогноз заболевания очень плохой. Поэтому медсестра должна смириться с тем фактом, что ее работа хоть и гуманна и достойна похвалы, но она не ведёт к положительной цели, то есть исцелению [4].

\section{Цель исследования}

Работа медсестер в стационарных отделениях связана с высокими требованиями как физического, так и психического характера, что может привести к ущербу для здоровья и низкому уровню удовлетворенности работой. Нейропсихологическая нагрузка возникает в основном изза эмоционального напряжения, связанного с ответственностью за жизнь пациента, с организацией работы или условиями труда. Мы часто ищем ответы на вопрос, сильно ли психически перегружены медсестры работающие в стационаре? Могут ли преодолевать чрезмерный стресс с которым ежедневно сталкиваются? Целью нашей работы является помощь в расширении знаний о психологической нагрузке медсестер в связи с оказанием сестринского ухода в стационарных отделениях.

Исходя из поставленной задачи, мы ставим следующие цели:

- выяснить, является ли чувство нехватки времени и высокая ответственность на работе причиной психологической нагрузки медсестер;

- выяснить, вызывает ли чрезмерное психическое напряжение у медсестер чувство усталости и нервозности;

- выяснить, является ли умственная нагрузка медсестер причиной снижения производительности труда и возникновения частых проблем и конфликтов.
На основании теоретических и практических знаний мы выдвинули следующие гипотезы:

- Г1 Мы предполагаем, что чувство нехватки времени на работе является причиной психологической нагрузки медсестер.

- Г2 Мы предполагаем, что психологическая нагрузка медсестер вызывает чувство усталости и нервозности у медсестер.

- Г3 Мы предполагаем, что психическое напряжение является причиной снижения работоспособности медсестер и возникновения частых проблем и конфликтов.

- Г4 Мы предполагаем, что образование связано со знанием техники релаксации для снятия стресса.

\section{Материалы и методы}

Для получения данных мы выбрали метод анкетирования. Мы использовали стандартизированную анкету Мейстера, чтобы оценить нагрузку медсестер. Microsoft Office Excel 2007 и STATISTICA v.10. использовались для статистической обработки. Для статистической оценки гипотез мы использовали коэффициент корреляции Спирмена, с помощью которого мы искали связь между двумя количественными переменными, и другой статистический тест, хи-квадрат Пирсона, для поиска связи между образованием и использованием методов релаксации. Группа состояла из 102 медсестер, работающих в стационарных отделениях больниц. Из общего числа 102 респондентов женщины составляли 97\%, а мужчины - 3\%. Отсюда следует, что женщины по-прежнему занимают доминирующее положение в профессии медсестры.

\section{Результаты исследований}

В следующих таблицах представлены результаты обработки полученных данных анкетирования с использованием методов статистической обработки. Оценка была основана на вопроснике Мейстера, и мы выясняли значимость различий в вопросах, которые включают отдельные факторы.

Г1 Мы предполагаем, что чувство нехватки времени на работе является причиной психологической нагрузки медсестер

При мониторинге зависимости вопросов №. 1, 3, 5 и суммарный коэффициент перегрузки (таблица 1), можно говорить о высокой корреляции, что понятно, учитывая, что этот коэффициент был создан как их сумма. Однако нас интересовало, является ли нехватка времени причиной психологического стресса. Эта связь была подтверждена коэффициентом корреляции 0,222 , который является значительным. Мы можем утверждать, что гипотеза 1 была подтверждена. 
Таблица 1. Коэффициенты корреляции для мониторинга коэффициента перегрузки

\begin{tabular}{|l|c|c|c|c|}
\hline \multirow{2}{*}{ Переменная } & \multicolumn{4}{c|}{ Корреляция Спирмена } \\
\hline & \multicolumn{2}{|c|}{ Отмеченные корреляции значимы на уровне переменных р<0,05 } \\
\hline Ot_1 & Вопрос 1 & Вопрос 3 & Вопрос 5 & FI \\
\hline Ot_3 & 1,000000 & 0,222161 & 0,270908 & 0,694430 \\
\hline Ot_5 & 0,222161 & 1,000000 & 0,259559 & 0,671627 \\
\hline FI & 0,270908 & 0,259559 & 1,000000 & 0,705665 \\
\hline
\end{tabular}

Г2 Мы предполагаем, что психологическая нагрузка медсестер вызывает чувство усталости и нервозности у медсестер.

В таблице 2 представлены коэффициенты корреляции как результаты отношений между вопросами, представляющими неспецифический фактор, и самим неспецифическим фактором, который был создан как их сумма. Вопрос № 7 представляющий чувства нервозности при психических нагрузках в значительной степени связан с усталостью и слабостью (вопрос № 9), что можно сказать, что гипотеза 2 была подтверждена. В результате чрезмерного психического напряжения заставляет медсестер чувствовать себя усталым и нервными.

\section{Таблица 2. Коэффициенты корреляции для мониторинга неспецифического фактора}

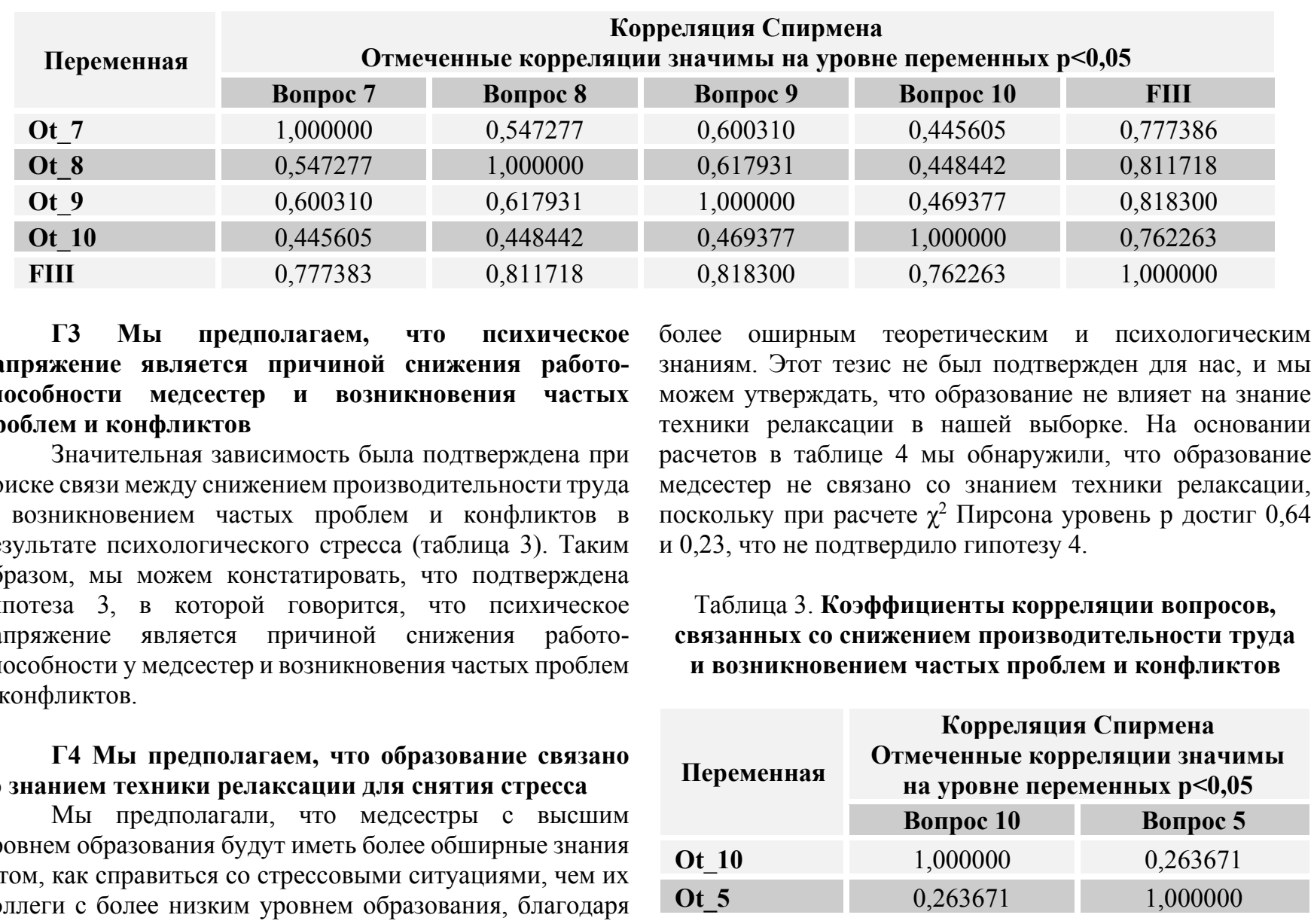


Таблица 4. Ожидаемые цифры, касающиеся регулярного использования комнаты медсестрами, выделенной работодателем для перерыва

\begin{tabular}{|c|c|c|c|c|c|c|c|}
\hline \multicolumn{8}{|c|}{ Количество меченых клеток $>$ 10, $\chi^{2}$ Пирсона: $3,3614949, \mathrm{sv}=5, \mathrm{p}=0.644442$} \\
\hline \multirow{2}{*}{ Ot_22 } & \multicolumn{6}{|c|}{ Образование } & \multirow{2}{*}{$\begin{array}{l}\text { Общая } \\
\text { линия }\end{array}$} \\
\hline & af & d & c & $\mathbf{a}$ & f & ab & \\
\hline $\mathrm{n}$ & 20,7058 & 16,94118 & 22,58824 & 22,58824 & 0,941176 & 12,23529 & 96,0000 \\
\hline $\mathrm{a}$ & 1,29412 & 1,05882 & 1,41176 & 1,41176 & 0,058824 & 0,76471 & 6,0000 \\
\hline Вместе & 22,0000 & 18,0000 & 24,0000 & 24,0000 & 1,0000 & 13,0000 & 102,000 \\
\hline \multicolumn{8}{|c|}{ Количество меченых клеток $>10, \chi^{2}$ Пирсона: $6,83219, \mathrm{sv}=5, \mathrm{p}=0,233423$} \\
\hline \multirow{2}{*}{ Ot_16 } & \multicolumn{6}{|c|}{ Образование } & \multirow{2}{*}{$\begin{array}{l}\text { Общая } \\
\text { линия }\end{array}$} \\
\hline & af & d & c & $\mathbf{a}$ & f & ab & \\
\hline $\mathrm{n}$ & 6,90196 & 5,64706 & 7,52941 & 7,52941 & 0,313725 & 4,07843 & 32,0000 \\
\hline a & 15,09804 & 12,35294 & 16,47059 & 14,47059 & 0,686275 & 8,92157 & 70,0000 \\
\hline Вместе & 22,0000 & 18,0000 & 24,0000 & 24,0000 & 1,0000 & 13,0000 & 102,000 \\
\hline
\end{tabular}

\section{Обсуждение}

Медсестра находится в постоянном контакте со многими стрессогенными факторами во время своей работы. Она часто сталкивается со смертью, страданиями, умирающими или неизлечимо больными людьми. Она ежедневно контактирует с людьми, которые по-разному реагируют на болезнь, на пребывание в больнице или вызывают конфликт. Если к этим проблемам добавятся кофликтные ситуации на рабочем месте или проблемы повседневной жизни, может случиться так, что медсестра попадает в трудную жизненную ситуацию. В связи с этим мы сосредоточили свое внимание на психологической нагрузке медсестер в оказании сестринской помощи в стационарных отделениях. В начале исследования мы ставим цели, из которых мы потом выводим гипотезы. Чтобы подтвердить или опровергнуть эти гипотезы, мы использовали стандартизированную анкету Мейстера. Анкета была заполнена 102 медсестрами, работающими в стационарных отделениях. Мы обратились к медсестрам из хирургических и нехирургических отделений, то есть из других стандартных отделений. Процент возврата анкеты составил $85 \%$. Демографические вопросы показали, что из 102 медсестер к которым мы обратились, наиболее многочисленную группу составили медсестры в возрасте от 30 до 39 лет, 41\%. 26\% респондентов были медсестрами в возрасте от 40 до 49 лет. 17\% медсестер были старше 50 лет. 16\% медсестер были моложе 29 лет.

При определении умственной нагрузки медсестер согласно опроснику Мейстера были оценены 3 компонента: перегрузка FI, монотонность FII и неспецифический фактор FIII. Мы оценили анкету по факторам и по отдельным вопросам. Впоследствии мы определили степень нагрузки. При индивидуальной оценке мы можем констатировать, что при коэффициенте перегрузки $25 \%$ медсестер имели тенденцию иметь более низкие оценки в ответах, что означало, что они не согласились с тезисом слабой перегрузки, напротив, 75\% согласились с перегрузкой. Второй фактор FII оказался высоким процентом - около 88\% - как несогласие с однообразием или утверждение, что работа будет малоинтересной. Мы записали относительно разные проценты с третьим неспецифическим фактором, где процентные различия могут быть вызваны разными типами больниц - университетскими и городскими. Оценивая отдельные элементы, мы исходили из превышения критических значений медианы. Сравнение с критическими значениями показывает, что медсестры оценивали отрицательное влияние ограничения по времени и длительную нагрузку на работе. Другие параметры были оценены положительно. В 2007 году Влкова провела исследование среди медсестер в гериатрических палатах, домах престарелых и агентствах по уходу на дому, используя анкету Мейстера. Она обнаружила наименьшую перегрузку, монотонность и наименьший неспецифический фактор у медсестер, работающих на дому. Эти сестры имели наибольшее удовлетворение от работы и меньше всего конфликтовали. Они испытывали низкую степень нервозности, усталости и перенасыщенности на работе по сравнению с другими группами [5]. Общая оценка анкеты Мейстера показывает, что медсестры были включены в уровень 2, который говорит о психической нагрузке, во время которой может быть продолжительное влияние субъективного состояния, соответственно низкая производительность. Немцова (2009) утверждает, что медсестры в гериатрических отделениях в Чешской Республике были отнесены к 1 классу, это значит, что эти нагрузки не влияют на здоровье или работоспособность. Поэтому можно предположить, что для медсестер, работающих с пожилыми людьми, предъявляются более высокие требования к физической выносливости [6]. В гипотезе 5, мы проверили, связано ли образование медсестер со знанием методов релаксации для преодоления стресса. На основании статистических расчетов мы обнаружили, что уровень образования опрошенных медсестер не связан со знанием техники релаксации, поскольку при расчете хи-квадрат уровень $p$ достиг 0,64 и 0,23, что не подтвердило гипотезу № 4 . Комачекова (2009) также получила дополнительные данные в своей работе, где она предполагала, что длительность практики будет влиять на использование 
эффективных стратегий борьбы со стрессом [7]. Но даже это предположение не подтвердилось.

\section{Выводы}

Исходя из теоретических знаний и результатов исследований, было бы целесообразно:

- создавать и укреплять хорошие межличностные отношения, так как работа в условиях нехватки времени негативно влияет на них;

- организовать, в сотрудничестве с руководством отделения, внерабочие встречи, которые будут одной из форм расслабления, но также помогут укрепить отношения между сотрудниками;

- повышать уровень коммуникабельности, которая составляет значительную часть повседневной деятельности медсестры;

- старатся не переносить свои личные проблемы на рабочее место, так как это негативно отражается не только на работе медсестры, но и на всей команде (больший риск ошибки);

- научиться быть настойчивым и сказать «НЕТ», пройти курс ассертивного поведения (индивидуально или через работодателя, если это позволяется);

- научиться правильно реагировать в конфликтных ситуациях и реагировать соответствующим, общественно приемлемым образом;

- научиться отдыхать - сделать перерыв, пополнить силы, освоить техники релаксации, иметь свои интересы;

- обратить внимание на здоровый образ жизни здоровое и сбалансированное питание, правильные физические нагрузки, физические упражнения, хорошее состояние, стрессоустойчивость, хорошее настроение, позитивный подход к жизни, качественный сон, правильное дыхание, закаливание и т.д.

Учитывая тот факт, что ни одна медсестра не имеет возможности встретиться с психологом на своем рабочем месте, мы рекомендуем связаться с работодателем через руководство отделения, чтобы убедиться, что медсестры имеют контакт с психологом, соответственно подготовить поддерживающую психологическую программу, которая позволила бы медицинским работникам справиться с накопленными эмоциями.

Работа медсестры - одна из самых много затратных профессий. Её основная задача - уход за больными. Медсестры, работающие у постели больного, занимают особенно важное место. Здесь буквально платит, что человек, привязанный к кровати, зависит от своей медсестры. Она - та, кто с ним, когда встает, когда засыпает, когда страдает от боли, когда переживает, но также она рядом когда пациент улыбается и радуется улучшению своего состояния или выздоравливает. Именно она проводит с ним 24 часа в сутки. Без самоотверженной работы медсестры лечение не было бы таким успешным. Что бы доктор ни делал для пациента, он никогда не заменит работу медсестры. Благодаря ее трудолюбию, терпению и любви к ближнему пациентам легче преодолевать пребыванием в больнице и двигаться к скорейшему выздоровлению. Поэтому очень важно обеспечить медсестрам здоровую рабочую атмосферу, так как чрезмерная нагрузка и стресс сопровождают их ежедневно и могут привести к выгоранию.

\section{Література}

1. Гучкова, М. 2007. Физическая нагрузка медсестер. B Sestra, ISSN 1210-0404, 2007, vol. 17, no. 6, с. 21.

2. Вансач, П. Избранные главы из этики, историческое развитие этики, основы этики, этика в социальной работе, Университет здравоохранения и социальной работы Св. Альжбеты Братислава, Институт социальных наук и здравоохранения бл. П. П. Гойдич в Прешове, Прешов 2011, с. 128, ISBN 978-80-8132-030-9.

3. Ёбанкова, М. 2007. Источники психосоциальной нагрузки в профессии медсестры. B Sestra, ISSN 1210-0404, 2007, vol.17, no. 7-8, c.18-19.

4. Балогова, Э. 2009. Сестринское дело как естественная стрессовая профессия. В книге «Медсестра и врач на практике», ISSN 1335 - 9444, 2009, том 8, №. 7-8, с. 46-47.

5. Влкова, J. 2007. Психические и физические нагрузки медсестер, работающих с гериатрическими пациентами. (диплом бакалавра). Брно: Масарикский университет, медицинский факультет, 2007, с.66.

6. Немцова, Z. 2010. Психическое и физическое напряжение медсестер, работающих с гериатрическими клиентами (бакалавриат). Пардубице. Университет Пардубице, ФЗС, 2010, с.77.

7. Комачекова, Д. 2009. Физический и психический стресс при оказании сестринской помощи - профилактика, защита и поддержка здоровья медсестры. В Sestra, ISSN 1210-0404, 2009, vol. 19, no. 7-8, с. 26-27.

8. Беловичова, М., Вансач, П. 2019. Отдельные аспекты медико-социальной помощи для длительно больных людей. Towarzystwo Slowaków w Polsce, Kraków, 2019, 153 p. ISBN 978-83-811110-9-6.

9. Угринова, Д. 2011. Психологическая нагрузка медсестер при оказании сестринской помощи (магистерская работа). Трнава: Трнавский университет, ФЗаСП, 2011, с. 76. 


\section{References}

1. Guchkova, M. 2007. Fizicheskaya nagruzka medsester. V Sestra, ISSN 1210-0404, 2007, vol. 17, no. 6, s. 21.

2. Vansach, P. Izbranny`e glavy` iz e`tiki, istoricheskoe razvitie e`tiki, osnovy` e`tiki, e`tika $v$ soczial`noj rabote, Universitet zdravookhraneniya i soczial`noj raboty`Sv.. Al’zhbety` Bratislava, Institut soczial ’ny`kh nauk i zdravookhraneniya bl. P. P. Gojdich v Preshove, Preshov 2011, s. 128, ISBN 978-80-8132-030-9.

3. Yobankova, M. 2007. Istochniki psikhosoczial’noj nagruzki v professii medsestry`. V Sestra, ISSN 1210-0404, 2007, vol.17, no. 7-8, s.18-19.

4. Balogova, E`. 2009. Sestrinskoe delo kak estestvennaya stressovaya professiya. V knige «Medsestra i vrach na praktike», ISSN 1335 - 9444, 2009, tom 8, \# 7-8, s. 46-47.

5. Vlkova, J. 2007. Psikhicheskie i fizicheskie nagruzki medsester, rabotayushhikh s geriatricheskimi paczientami. (diplom bakalavra). Brno: Masarikskij universitet, mediczinskij fakul tet, 2007, s.66.

6. Nemczova, Z. 2010. Psikhicheskoe i fizicheskoe napryazhenie medsester, rabotayushhikh s geriatricheskimi klientami (bakalavriat). Pardubicze. Universitet Pardubicze, FZS, 2010, s.77.

7. Komachekova, D. 2009. Fizicheskij i psikhicheskij stress pri okazanii sestrinskoj pomoshhi - profilaktika, zashhita i podderzhka zdorov`ya medsestry`. V Sestra, ISSN 1210-0404, 2009, vol. 19, no. 7-8, s. 26-27.

8. Belovichova, M., VANSACH, P. 2019. Otdel`ny`e aspekty` mediko-soczial`noj pomoshhi dlya dlitel ’no bol`ny`kh lyudej. Towarzystwo Slowaków w Polsce, Kraków, 2019, 153 p. ISBN 978-83-811110-9-6.

9. Ugrinova, D. 2011. Psikhologicheskaya nagruzka medsester pri okazanii sestrinskoj pomoshhi (magisterskaya rabota). Trnava: Trnavskij universitet, FZaSP, 2011, s. 76.

Дата надходження рукопису до редакції: 21.01.2020 p.

Целью исследования является содействие расширению знаний о психологическом бремени медсестер в связи с оказанием сестринского ухода в стационарных отделениях.

Материалы и методы. Группа состояла из 102 медсестер, работающих в стационарных отделениях. Проводилось исследование: являются ли чувство нехватки времени и высокая ответственность на работе причиной психологической нагрузки на медсестер и было ли чрезмерное психическое напряжение и усталость у медсестер, причиной снижения работоспособности, возникновения частых проблем и конфликтов. Оценка была основана на вопроснике Мейстера, и мы выяснили значимость различий в вопросах, которые включают отдельные факторы. Для подтверждения гипотезы мы использовали инструменты статистики коэффициента корреляции Спирмена и хи-квадрат Пирсона. Мы приняли решение о значимости различий на основе рассчитанного значения и уровня значимости 0,05 .

Результаты. Анализ показал, что нехватка времени является причиной психического стресса. Исследования также показывают, что чрезмерное психическое напряжение вызывает у медсестер усталость и нервозность, а также является причиной снижения работоспособности у медсестер и возникновения частых проблем и конфликтов.

Выводы. Работа медсестры - одно из самых многозатратых занятий. Его основная задача - уход за больными. Медсестры, работающие у постели больного, занимают особенно важное место. Поэтому очень важно обеспечить медсестрам здоровую рабочую среду, так как чрезмерная нагрузка и стресс сопровождают их ежедневно и могут привести к выгоранию.

Ключевые слова: медицинска сестра, психическое бремя, физическая активность, уход за больными.

Метою дослідження є сприяння розширенню знань про психологічний тягар медсестер в зв'язку 3 наданням сестринського догляду в стаціонарних відділеннях.

Матеріали та методи. Група складалася з 102 медсестер, які працюють в стаціонарних відділеннях. Проводилось дослідження: чи є відчуття браку часу і висока відповідальність на роботі причиною психологічного навантаження на медсестер і чи було надмірне психічне напруження і втома у медсестер причиною зниження працездатності, виникнення частих проблем і конфліктів. Оцінка була заснована на опитувальнику Мейстера, і ми з'ясували значимість відмінностей в питаннях, які включають окремі фактори. Для підтвердження гіпотези ми використовували інструменти статистики: коефіцієнта кореляції Спірмена і хі-квадрат Пірсона. Ми прийняли рішення про значущість відмінностей на основі розрахованого значення і рівня значущості 0,05 .

Результати. Аналіз показав, що нестача часу є причиною психічного стресу. Дослідження також показують, що надмірне психічне напруження викликає у медсестер втому і нервозність, а також є причиною зниження працездатності і виникнення частих проблем і конфліктів.

Висновки. Робота медсестри - одне 3 найбільш багатозатратих занять. Його основне завдання - догляд за хворими. Медсестри, які працюють біля ліжка хворого, займають особливо важливе місце. Тому дуже важливо забезпечити медсестрам здорове робоче середовище, так як надмірне навантаження і стрес супроводжують їх щодня і можуть призвести до вигоряння.

Ключові слова: медична сестра, психічний тягар, фізична активність, догляд за хворими. 
The aim of the research is to contribute to the expansion of knowledge about the psychological ballast of nurses in connection with the provision of nursing care in inpatient wards.

Research file and aim of the research. The research file consisted of 102 nurses working in hospital wards. We investigated whether the feeling of time pressure and high responsibility at work are the cause of the psychological ballast on the nurses. We examined whether excessive mental stress in nurses felt tired, nervous, and also whether it was the cause of reduced performance in nurses and the occurrence of frequent problems and conflicts.

Methods. The evaluation was based on Meister's questionnaire and we found out the significance of differences in questions that include individual factors. We used the tools of inductive statistics Spearman's correlation coefficient and Pearson's chi-square to verify the hypotheses. We make a decision on the significance of differences based on the calculated value and the significance level of 0.05 .

Results. The analysis found that time pressure is the cause of mental stress. Our research also shows that excessive mental stress causes fatigue and nervousness in nurses and is the cause of reduced performance in nurses and the occurrence of common problems and conflicts.

Conclusions. The work of a nurse is one of the most demanding occupations. Its main task is nursing care for the sick. Nurses working at the patient's bedside have a particularly important place. Therefore, it is essential to provide nurses with a healthy work environment, as excessive workload and stress accompany them on a daily basis and can result in burnout.

Key words: nurse, mental ballast, physical ballast, nursing care.

Конфлікт інтересів: відсутній.

Conflicts of interest: authors have no conflicts of interest to declare.

\section{Відомості про авторів}

doc. PhDr. Popovičová Mária, PhD. - Высшая школа здравоохранения и социальной работы св. Алжбеты, Братислава, н.о. филиал бл. Метода Доминика Тричку, Словакия.

maria.popovic911@gmail.com.

doc. RNDr. Mgr. Barkasi Daniela, PhD. - Высшая школа здравоохранения и социальной работы св. Алжбеты, Братислава, н.о .филиал бл. Метода Доминика Тричку, Словакия.

daniela.barkasi@gmail.com. 